\title{
Sectoral Differences in Labor Productivity Growth: Estimation and Modeling
}

\author{
Roberto Roson ${ }^{1,2,3, *}$ \\ ${ }^{1}$ Department of Economics, Ca'Foscari University Venice, Cannaregio S. Giobbe 873, 30121, \\ Venezia, Italy \\ ${ }^{2}$ GREEN Bocconi University, Milan, Italy \\ ${ }^{3}$ Loyola Andalusia University, Spain \\ *Correspondence: E-mail: roson@unive.it
}

Received: January 23, 2019 Accepted: February 25, 2019 Published: March 13, 2019

doi: 10.5296/rae.v11i1.14145 URL: https://doi.org/10.5296/rae.v11i1.14145

\begin{abstract}
This study provides some empirical evidence and quantification of differences in labor productivity among industries and countries. Using a recently available data base of value added per worker, country and time fixed effects are estimated first for various industries. Results are subsequently elaborated, to identify some time trends and sectoral profiles by country, which are in turn employed in a cluster analysis, summarizing some salient characteristics of industrial labor productivity in different economies. The empirical exercise is motivated by the possible employment of its findings in the construction of long-run economic growth scenarios, by means of Computable General Equilibrium (CGE) models. It is found that: (a) Manufacturing is normally the fastest growing sector and its performance is strongly correlated with the aggregate productivity growth; (b) differences in the rates of agricultural productivity gains are relatively minor; (c) slow-growing countries are characterized by slow-growing Services.
\end{abstract}

Keywords: Labor productivity, structural change, economic dynamics, cluster analysis

JEL Codes: F43, C23, C82, O11, O47. 


\section{Introduction}

Labor productivity and productivity in general, does not vary uniformly, neither across sectors, nor across countries (Duarte \& Restuccia, 2010). Indeed, differential productivity growth is one key factor of structural change in the economic systems, and probably the most important one (Swiecki, 2017). Several implications of different growth rates have been investigated in the literature, e.g.: relevance and empirics of the so-called "Baumol's disease" (Baumol, 1986; Triplett \& Bosworth, 2003; Young, 2014); specialization and international trade (McMillan \& Rodrik, 2011; Caron \& Markusen, 2014); "premature deindustrialization" (Rodrik, 2016).

However, empirical works aimed at measuring how much (labor) productivity varies by industry and region are quite limited, primarily because of the lack of a consistent data base with sufficient coverage, including developing countries and possibly informal markets. Such a high quality information source is now available (de Vries et al., 2015), and this paper exploits that data source (like in Üngör (2013)) to highlight some key characteristics of differential labor productivity growth among sectors and countries.

This source is the Groeningen Growth and Development Centre GGDC 10-Sector Database, providing a long-run internationally comparable dataset on sectoral productivity performance. It consists of series for 11 countries in Africa, 11 countries in Asia, 2 countries in the Middle East and North Africa, 9 in Latin America, the US and 8 European countries. From the series of real value added and employment, an unbalanced panel of labor productivity annual variations, covering 10 industries, 42 countries, and ranging from 1949 to 2013, can be readily obtained.

Disentangling the contribution of the various sectors to the overall variation of (labor) productivity, and the implied changes in the structure of the economic systems, may be of fundamental importance in many theoretical and empirical studies dealing, for instance, with: conditional convergence (Sorensen, 2001; Castellacci et al., 2014), demand-driven endogenous productivity (Matsuyama, 2017), regional structural change (Fagerberg, 2000; Chen et al., 2011), skill-based structural change (Buera et al., 2015), to name a few.

In particular, the main motivation for this empirical exercise is given by the possible employment of its findings for the construction of long-run economic growth scenarios, by means of Computable General Equilibrium (CGE) models. Whereas these models are usually characterized by a detailed account of the economic structure, which is often essential when dealing with sector specific impacts and policies, they are also normally calibrated on the basis of some past data (e.g., input-output tables or their social accounting matrix (SAM) extensions), meaning that they mirror an economic structure quite different from the one we could possibly observe in the future. In a companion paper, Roson and van der Mensbrugghe (2018) analyze the variations in the industrial structure induced by income-sensitive patterns of final consumption, and how these changes can be captured by a flexible demand system. Results in this paper allow to make a further step: accounting for variations in relative productivity, occurring over time and at different stages of economic development. 


\section{1) Macrothink}

\section{Methodology}

Ten sectors are considered in the GGDC dataset: Agriculture, hunting, forestry and fishing (AGR); Mining and quarrying (MIN); Manufacturing (MAN); Electricity, gas and water supply (UTI); Construction (CON); Wholesale and retail trade, hotels and restaurants (TRH); Transport, storage, and communication (TRC); Finance, insurance, real estate and business services (FIN); Government services (GOV); Community, social and personal services (SER).

For each sector, an unbalanced panel of annual changes in labor productivity was employed in a fixed effects regression, aimed at deriving two sets of parameters: a series of time variables and a set of intercept parameters by country.(Note 1) Subsequently, the time series were analyzed, to identify some trends in productivity variations. For each sector, a piecewise linear function was interpolated, as shown in Figure 1 for the case of Manufacturing. The break point is endogenously determined in each regression, to maximize the good-ness of fit. Table 1 presents the findings in terms of: (a) slope coefficient before the break; (b) slope coefficient after the break; (b) year of the break. A positive (negative) slope coefficient indicates accelerating (decelerating) labor productivity growth.

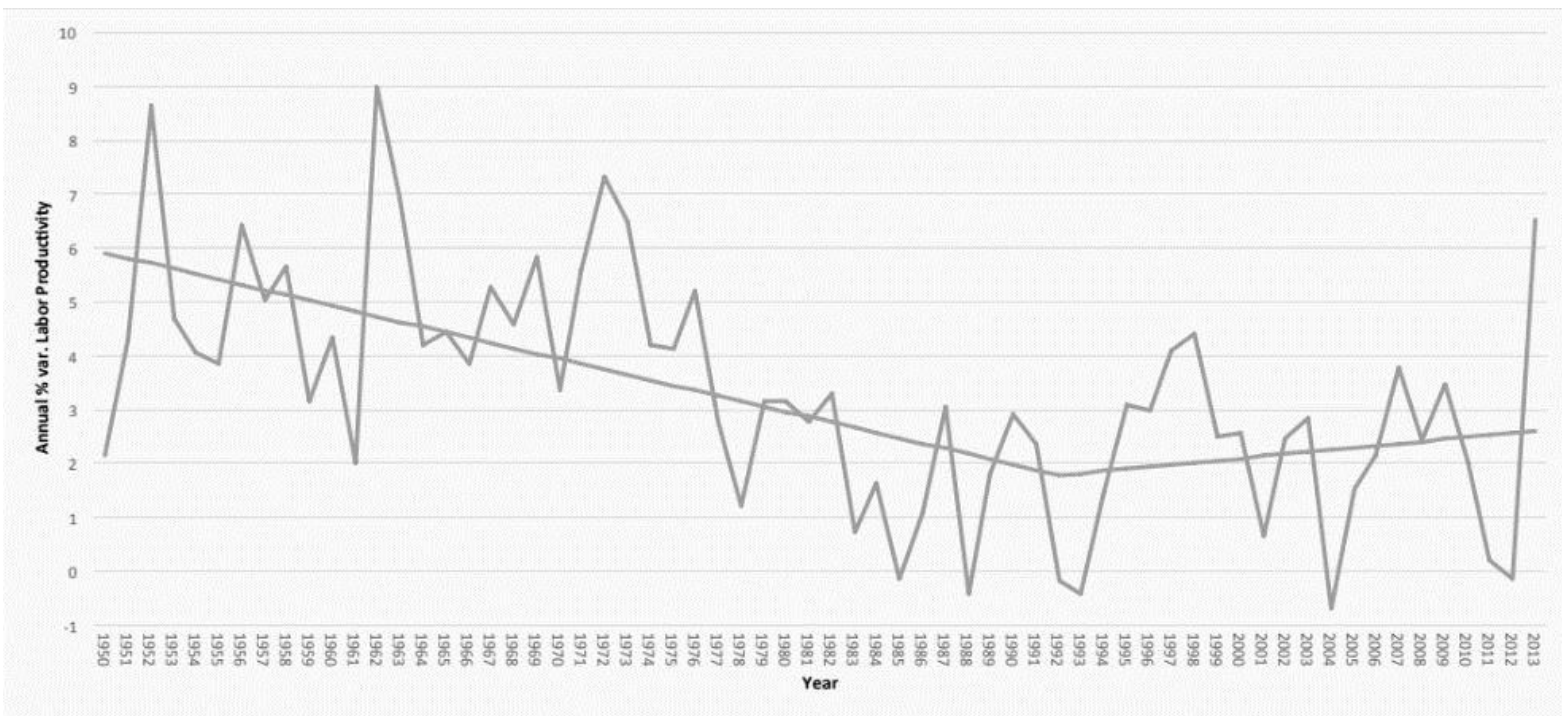

Figure 1. Semi-linear Trend for Labor Productivity in Manufacturing

An interesting question, which is left to future research, is why structural breaks are detected in specific years, especially when the slope coefficient changes significantly, or varies in sign, like in the case of Mining (2004), Construction (2001), Finance (1954) and Government (1959). 
Table 1. Sectoral Trend Analysis

\begin{tabular}{|c|c|c|c|}
\hline Sector & Slope before & Slope after & Break year \\
\hline AGR & -0.006 & -0.006 & - \\
\hline MIN & -0.032 & -0.436 & 2004 \\
\hline MAN & -0.098 & +0.040 & 2002 \\
\hline UTI & -0.060 & -0.242 & 2004 \\
\hline $\mathrm{CON}$ & -0.127 & +0.338 & 2001 \\
\hline TRH & -0.140 & +0.022 & 1981 \\
\hline TRC & -0.030 & +0.014 & 1981 \\
\hline FIN & +1.032 & -0.054 & 1954 \\
\hline GOV & -0.299 & -0.019 & 1959 \\
\hline SER & -0.046 & +0.032 & 1979 \\
\hline
\end{tabular}

The fixed effects estimated at the country level account instead for some specific characteristics of the different economies, influencing the labor productivity growth in each sector, in addition to the general worldwide tendency. Therefore, it is a way of indirectly considering factors like the institutional setting, natural conditions, but also the internal composition of the sectors.

Since the fixed effects regression estimates one parameter for all regions in the 10 panels, each country is characterized by a vector of 10 parameter values, expressing its specific "productivity profile". These profiles have been the subject of a cluster analysis, aimed at finding similarities in groups of countries. To this end, a measure of vector distance is used, and countries are grouped in the same cluster if the distance among themselves is significantly lower that between other countries. The data are clustered by the k-means method, using the algorithm by Hartigan and Wong (1979) as implemented in the R statistical package, which aims to partition the points into k groups such that the sum of squares from points to the assigned cluster centres is minimized. At the minimum, all cluster centres are at the mean of their Voronoi sets (the set of data points, which are nearest to the cluster centre). The k-means method assumes that the number of cluster is specified beforehand. Of course, the higher the number of clusters, the lower the within-cluster distance. Starting from the case of two clusters, the number of clusters has been progressively increased, stopping the process when no significant decreases in the average internal distance were detected.

In this way, three major clusters have been identified. In one cluster, for illustrative purposes labelled "Rising", there are several high growth countries of the Far East (including China and South Korea) and Botswana. In the second cluster ("Steady") there are all European countries, Mauritius, Nigeria, Egypt, India, Indonesia, Japan and other Asian countries. In the remaining group ("Lagging") we can find the U.S., all Latin America and most of the African countries. The presence of the United States in this latter group confirms the empirical 


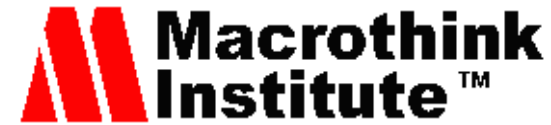

findings of the literature on "conditional" or "club" convergence (see, e.g., Quah (1997)).

\section{Results}

The primary purpose of the exercise is detecting a (short-run) trend of labor productivity growth at the sectoral level. To this aim, the last estimated values in the linear piecewise regressions, expressing the global trend in each industry, were added to the country fixed effects, and some averages have been computed. Table 2 presents those average labor productivity growth rates for the three clusters(Note 2) and for the whole set of countries.

Table 2. Labor Productivity Growth Rates

\begin{tabular}{lcccccccccc}
\hline Cluster & AGR & MIN & MAN & UTI & CON & TRH & TRC & FIN & GOV & SER \\
\hline Rising & 6.23 & 13.06 & 11.93 & 7.37 & 10.06 & 5.00 & 12.99 & 1.48 & 4.27 & 6.24 \\
Steady & 7.00 & 8.44 & 8.20 & 4.36 & 7.60 & 3.38 & 11.41 & 1.96 & 5.47 & 3.88 \\
Lagging & 5.17 & 5.07 & 5.34 & 2.68 & 5.63 & 0.24 & 9.34 & -0.18 & 2.94 & 2.68 \\
Global & 6.04 & 7.55 & 7.42 & 4.02 & 7.04 & 2.16 & 10.68 & 0.90 & 4.12 & 3.67 \\
\hline
\end{tabular}

Since most of the works on labor productivity in the literature focus on the three macro-sectors Agriculture, Manufacturing and Services, the results could be better appreciated after weighted aggregation, using labor income industrial shares in the value added. (Note 3) The results are presented in Table 3, including the corresponding total economy-wide productivity growth.

Table 3. Aggregated Productivity Growth Rates

\begin{tabular}{lrrrr}
\hline Cluster & AGR & MAN & SER & TOT \\
\hline Rising & 6.23 & 11.43 & 5.65 & 8.00 \\
Steady & 7.00 & 7.88 & 5.00 & 5.93 \\
Lagging & 5.17 & 5.32 & 2.34 & 3.16 \\
\hline
\end{tabular}

Several interesting considerations emerge quite naturally. First, Manufacturing is always the fastest growing sector, in terms of value added per worker, at least in the time period considered. In addition, labor productivity growth in Manufacturing is strongly correlated with productivity growth overall. Fast growing economies are characterized by a dynamic Manufacturing service, which is still, somehow, "the engine of growth" (Haraguchi et al., 2017). The fact that aggregate growth is strong when growth in Manufacturing is strong suggests that this sector may generate positive externalities to the rest of the economic 
system.

Labor productivity growth in Agriculture is around 6\% per year, but regional differences are less significant. By contrast, one can notice a clear divide be-tween Lagging regions and the rest about labor productivity in the Services.

\section{Conclusions}

Different economies do not simply grow at different speeds: they do so in different ways. A simple exercise has been presented in this work, where data from the GGDC 10 sectors database has been elaborated, in order to highlight some salient characteristics of the labor productivity dynamics. The key qualitative insights could be summarized as follows: (a) Manufacturing is normally the fastest growing sector and its performance is strongly correlated with the aggregate productivity growth; (b) differences in the rates of agricultural productivity gains are relatively minor; (c) slow-growing countries are characterized by slow-growing Services.

The exercise presented in this paper is a purely empirical one. Although some implications of the findings are quite obvious, no attempt has been made to provide a theoretical justification or interpretation. On the other hand, several contributions in this direction can be easily found in the literature, whereas the empirical evidence is disproportionately limited.

Several interesting issues are therefore left for future research. For instance, economic historians could explain why some years appear as turning points in the labor productivity trends. Development (and international) economists could contribute to a better understanding of the central role of Manufacturing. In addition, since we have focused here on labor productivity only, further empirical analysis could shed some light on the sources of the gains. Are they mainly due to factor-specific productivity, possibly linked to human capital? Are they related to capital deepening? If so, why capital may affect labor productivity differently in the different industries?

One major limitation of the exercise is due to the fact that labor was considered as a single factor, whereas a quite natural extension could take into account several classes of workers, possibly starting with a distinction between skilled and unskilled. That development would therefore provide a link with the literature on income distribution, polarization and specialization in the labor market, returns on education, etc.

\section{References}

Baumol, W. J. (1986). Productivity Growth, Convergence and Welfare: What the Long-Run Data Show. The American Economic Review, 76(5), 1072-1085.

Buera, F. J., Kaboski, J. P., \& Rogerson, R. (2015). Skill Biased Structural Change. NBER Working Paper 21165. https://doi.org/10.3386/w21165 


\section{MInstitute Macrothink}

Caron, J., \& Markusen, J. R. (2014). International Trade Puzzles: a Solution Linking Production and Preferences. The Quarterly Journal of Economics, 129(3), 1501-1552. http://dx.doi.org/10.1093/qje/qju010

Castellacci, F., Los, B., \& Vries, G. J. (2014). Sectoral productivity trends: convergence islands in oceans of non-convergence. Journal of Evolutionary Economics, 24, 983-1007. http://dx.doi.org/10.1007/s00191-014-0386-0.

Chen, S., Jefferson, G. H., \& Zhang, J. (2011). Structural change, productivity growth and industrial transformation in China. China Economic Review, 22(1), 133-150. http://dx.doi.org/10.1016/j.chieco.2010.10.003

De Vries, G., de Timmer, M., \& de Vries, K. (2015). Patterns of structural change in developing countries. In: Weiss, J., Tribe, M. (Eds.), Routledge Handbook of Industry and Development. Routledge, pp. 65-83. http://dx.doi.org/10.4324/9780203387061

Duarte, M., \& Restuccia, D. (2010). The role of the structural transformation in aggregate productivity. The Quarterly Journal of Economics, 125, 129-173. http://dx.doi.org/10.1162/qjec.2010.125.1.129

Fagerberg, J. (2000). Technological progress, structural change and productivity growth: a comparative study. Structural Change and Economic Dynamics, 11(4), 393-411. http://dx.doi.org/10.1016/S0954-349X(00)00025-4

Haraguchi, N., Cheng, C. F., \& Smeets, E. (2017). The importance of manufacturing in economic development: Has this changed? World Development, 93, 293-315. http://dx.doi.org/10.1016/j.worlddev.2016.12.013

Hartigan, J. A., \& Wong, M. A. (1979). A k-means clustering algorithm. Applied Statistics, 28, 100-108. https://doi.org/10.2307/2346830

Matsuyama, K. (2017). Engel's law in the global economy: Demand induced patterns of structural change and trade across countries.

McMillan, M., \& Rodrik, D. (2011). Globalization, Structural Change and Productivity Growth. NBER Working Paper w17143. https://doi.org/10.3386/w17143

Quah, D. T. (1997). Empirics for growth and distribution: Stratification, polarization, and convergence clubs. Journal of Economic Growth, 2(1), 27-59. https://doi.org/10.1023/A:1009781613339

Rodrik, D. (2016). Premature deindustrialization. Journal of Economic Growth, 21, 1-33. https://doi.org/10.1007/s10887-015-9122-3

Roson, R., van der Mensbrugghe, D. (2018). Demand-driven structural change in general equilibrium models. In Scandizzo, L. (Ed.), Social Accounting Matrices and Computable General Equilibrium Models: The State of the Art and Prospects for the Future. Springer. https://doi.org/10.1007/978-3-319-58533-8_2

Sorensen, B. A. (2001). Comparing Apples to Oranges: Productivity Convergence and 
Measurement across Industries and Countries: Comment. The American Economic Review, 91(4), 1160-1167. https://doi.org/10.1257/aer.91.4.1160

Swiecki, T. (2017). Determinants of structural change. Review of Economic Dynamics, 24, 95-131. https://doi.org/10.1016/j.red.2017.01.007

Triplett, J. E., \& Bosworth, B. P. (2003). Productivity Measurement Issues in Services Industries: Baumol's Disease Has Been Cured. Economic Policy, September, 23-33.

Üngör, M. (2013). De-agriculturalization as a result of productivity growth in agriculture. Economics Letters, 119, 141-145. https://doi.org/10.1016/j.econlet.2013.02.009

Young, A. (2014). Structural transformation, the mismeasurement of productivity growth, and the cost disease of services. American Economic Review, 104(11), 3635-3667. http://dx.doi.org/10.1257/aer.104.11.3635

\section{Notes}

Note 1. Details of the ten panel regressions are available on request.

Note 2. The ten values reported in Table 2 for each cluster correspond to a geometrical "centre" for the cluster, as computed by the k-means algorithm.

Note 3. The shares have been obtained from the 2011 GTAP SAM, with a consistent aggregation of industries and regions.

\section{Copyright Disclaimer}

Copyright for this article is retained by the author(s), with first publication rights granted to the journal.

This is an open-access article distributed under the terms and conditions of the Creative Commons Attribution license (http://creativecommons.org/licenses/by/3.0/). 